\title{
Letter to the Editor
}

\section{Tom Mala $^{1,2,3}$ (D) $\cdot$ Monica Chahal-Kummen ${ }^{1,3} \cdot$ Jon Kristinsson $^{1}$}

Received: 14 April 2021 / Revised: 20 April 2021 / Accepted: 23 April 2021 / Published online: 24 June 2021

(C) The Author(s), under exclusive licence to Springer Science+Business Media, LLC, part of Springer Nature 2021

Dear Editor,

We have read the paper "Long-term Emergency Department Visits and Readmissions After Laparoscopic Roux-en-Y Gastric Bypass: a Systematic Review" with great interest. The authors present highly relevant findings for all personnel involved in handling and follow-up of patients post Roux-en-Y gastric bypass thus contributing to the emerging evidence and focus on abdominal pain after bariatric surgery [1]. In their systematic review, although incorporating limitations such as restricted long-term data availability, retrospective data, and data heterogeneity, they find indications of longterm emergency department visits and hospital admissions mostly for acute abdominal pain in close to one in three patients. They stress the need for more prospective longitudinal data which is highly supported. Importantly, a recent paper found that despite extensive diagnostic work-up during emergency admission for abdominal pain after Roux-en-Y gastric bypass including computed tomography $(75 \%)$ and diagnostic laparoscopy (22\%), a significant subset of the patients (48\%) remained without a diagnosis of cause of symptoms [2]. Furthermore, a substantial number of patients may develop chronic abdominal pain and symptoms post Roux-en-Y gastric bypass $[3,4]$. These patients may not all necessarily end up in the emergency department. We previously found that one in three patients reported chronic abdominal pain up to 5 years after Roux-en-Y gastric bypass [5]. These aspects of abdominal symptoms should be confronted and handled during follow-up consultations as they may impact quality of life $[3,5]$. Such focus may also reduce emergency department readmission rates and the risk for developing chronic

Tom Mala

tommenmala@gmail.com; tommal@ous-hf.no

1 Department of Endocrinology, Morbid Obesity and Preventive Medicine, Oslo University Hospital, Pb, 49500424 Oslo, Norway

2 Department of Pediatric and Gastrointestinal Surgery, Oslo University Hospital, Pb, 49500424 Oslo, Norway

3 Institute of Clinical Medicine, The University of Oslo, Oslo, Norway prescription and use of analgesics. This is an important aspect as the use of opioids has been suggested increased after bariatric surgery [6]. It is essential that patients opting for Rouxen-Y gastric bypass are aware of not only the risk of acute but also chronic abdominal pain. Similar findings may also apply to other bariatric procedures with even less available knowledge. Further research of risk factors, etiology, and impact of these symptoms is required to guide patients and their physicians in selection of bariatric or metabolic procedure, to ease symptoms and to improve outcome and patient satisfaction after surgery.

\section{Declarations}

Conflict of Interest The authors declare no conflict of interest.

\section{References}

1. van Olst N, van Rijswijk AS, Mikdad S, et al. Long-term emergency department visits and readmissions after laparoscopic Roux-en-Y gastric bypass: a systematic review. Obes Surg 2021 Apr 4. 10.1007/s11695-021-05286-0. Online ahead of print.

2. Zaigham H, Ekelund M, Regnér S, et al. Abdominal pain after gastric bypass in the acute general surgical care setting. Surg Obes Relat Dis. 2020;16(12):2058-67.

3. Chahal-Kummen M, Blom-Høgestøl IK, Eribe I, et al. Abdominal pain and symptoms before and after Roux-en-Y gastric bypass. BJS Open. 2019;3(3):317-26.

4. Gormsen J, Burcharth J, Gögenur I, Helgstrand F Prevalence and risk factors for chronic abdominal pain after Roux-en-Y gastric bypass surgery. Ann Surg 2021;273(2):306-314.

5. Høgestøl IK, Chahal-Kummen M, Eribe I, et al. Chronic abdominal pain and symptoms 5 years after gastric bypass for morbid obesity. Obes Surg. 2017;27(6):1438-45.

6. Maciejewski ML, Smith VA, Berkowitz TSZ, et al. Long-term opioid use after bariatric surgery. Surg Obes Relat Dis. 2020;16(8): $1100-10$

Publisher's Note Springer Nature remains neutral with regard to jurisdictional claims in published maps and institutional affiliations. 